\title{
Oxidation Behavior of Nanostructured TiAIN and AlCrN Thin Coatings on ASTM-SA213-T-22 Boiler Steel
}

\author{
Vikas Chawla $^{\mathrm{a} *}$, Amita Chawla ${ }^{\mathrm{b}}$, Buta Singh Sidhu ${ }^{\mathrm{c}}$, S. Prakash ${ }^{\mathrm{d}}$ and D. Puri ${ }^{\mathrm{d}}$ \\ ${ }^{a}$ Mechanical Engineering Department, F.C.E.T., Ferozepur-152004, India \\ ${ }^{\mathrm{b}}$ Chemistry Department, Government Brijindra College, Faridkot -151203, India \\ ${ }^{\mathrm{c}}$ Punjab Technical University (P.T.U.), Jalandhar -144001, India \\ ${ }^{\mathrm{d}}$ Metallurgical \& Materials Engineering Department, I.I.T. Roorkee, Roorkee-247667, India \\ *Corresponding Author: vikkydmt@gmail.com
}

\begin{abstract}
Metals and alloys gets oxidized when exposed to elevated temperatures in air or highly oxidizing environments, such as combustion gas with excess of air or oxygen. They often rely on the oxidation reaction to develop a protective oxide scale to resist corrosion attack. In the present study, nanostructured TiAlN and AlCrN thin films were deposited by physical vapour deposition process on T-22 boiler steel (ASTM-SA213-T-22). Cyclic oxidation studies in air were conducted at $900^{\circ} \mathrm{C}$ temperature in the laboratory using silicon carbide furnace. The weight gain was measured after each cycle and visually examined the surface morphology of the oxidized samples was studied using FE-SEM with EDAX attachment and XRD analysis. The results obtained showed the better performance of AlCrN coated T-22 boiler steels then the TiAlN coated and uncoated T-22 boiler steel.
\end{abstract}

Keywords: Nanostructured coating, High temperature oxidation, Oxide Scale, Physical vapour deposition, Scale morphology.

\section{INTRODUCTION}

Coatings play crucial role to safeguard the materials of high temperature equipments, particularly for boilers and gas turbine engines against the oxidation and corrosion attacks [1]. Recent studies show that $80 \%$ of the total cost for the protection of metals is related to coating application [2]. Coatings provide a way of extending the limits of use of the materials at the upper end of their 
performance capabilities, by alloying the mechanical properties of the substrate materials to be maintained while protecting them against wear, oxidation and corrosion [3]. Although protective surface treatments are widely used at low temperature, the use of these at elevated temperature is relatively more recent [4]. In many tribological applications, hard coatings of metal nitrides are now commonly used [5]. The major properties required for such coatings are hardness and wear resistance. However, because of severe operating conditions, there is a need to combine mechanical features with corrosion resistance properties.

Physical vapor deposition technique (ion plating, sputtering, and arc evaporation) provides a promising ground for the deposition of these hard coatings by the formation of dense adhesive film at low deposition temperatures. Corrosion protection capability of physical vapor deposited (PVD) coatings is widely reported in literature [6]. Since the commercialization of physical vapor deposited (PVD) TiN coatings in early 1980s, transition metal nitrides based hard coatings have been successfully used for the materials protection particularly to improve cutting tools lifetime [7]. This type of coating, however, suffered severe oxidation at the temperatures 550 or $600^{\circ} \mathrm{C}$ [8]. A possible solution was found in consideration to the fact that both TiN and TiAlN have the same crystallographic structure (FCC), and therefore addition of Al atoms to the TiN matrix in the 1990s. At high temperature exposures, a very dense and strongly adhesive $\mathrm{Al}_{2} \mathrm{O}_{3}$ film is observed because of diffusion of $\mathrm{Al}$ atoms to the surface, which stops further oxidation [8, 9]. Since the addition of aluminum increases the oxidation resistance of Ti-N coatings, a similar effect on the oxidation resistance of $\mathrm{Cr}-\mathrm{N}$ coatings should be expected [10]. It has been reported that the hardness, oxidation resistance and the tribological properties improve with increasing Al-content up to $70-75 \%$ in the AlCrN coatings as long as fcc-structure is predominant. For higher aluminum content, hcp-structure starts to form and thus the oxidation resistance deteriorates [11].

Nanostructured coatings are reported to provide surface characteristics (hardness, wear resistance etc) superior to those of conventional coatings. Despite that several potential advantages have been noted, the technology is yet to be established for use in industrial applications [12]. Present study investigates the effects of nanostructured TiAlN and AlCrN thin coatings on the oxidation behavior of T-22 steel under the cyclic heating conditions. Some power plants in India are using T-22 grade as boiler tubes material due to its performance in stringent service conditions of pressure and temperature. A front-loading Balzer's rapid coating system (RCS) machine (make Oerlikon Balzers, Swiss) was used for the deposition of the coatings. The purpose of this study is to develop high temperature oxidation, erosion and corrosion resistant materials by thin film coatings.

\section{EXPERIMENTAL DETAILS}

\subsection{Selection of Substrate Material}


The substrate material used is: $2.25 \mathrm{Cr}-1 \mathrm{Mo}$ steel ASTM-SA213-T-22 (T22). This material is used as boiler tube materials in some of the power plants in northern India. T-22 boiler steel has a wide range of applications in boilers, especially where the service conditions are more stringent from the point view of temperature and pressure. The chemical composition of T-22 boiler steel is as reported in Table 1.

Table 1: Chemical composition (wt \%) of T-22 Boiler Steel (ASTM code SA213-T-22) :

\begin{tabular}{ccccccccc} 
Elements & $\mathrm{C}$ & $\mathrm{Mn}$ & $\mathrm{Si}$ & $\mathrm{S}$ & $\mathrm{P}$ & $\mathrm{Cr}$ & $\mathrm{Mo}$ & $\mathrm{Fe}$ \\
\hline Nominal & 0.15 & $0.3-0.6$ & 0.5 & 0.03 & 0.03 & $1.9-2.6$ & $0.87-1.13$ & Bal. \\
Actual & 0.165 & 0.355 & 0.115 & 0.00153 & 0.02026 & 2.646 & 0.90275 & Bal.
\end{tabular}

Specimens with dimensions of approximately $20 \mathrm{~mm} \times 15 \mathrm{~mm} \times 5 \mathrm{~mm}$ were cut from the alloy sheet. Polished using emery papers of 220, 400, 600 grit sizes and subsequently on 1/0, 2/0, 3/0, and $4 / 0$ grades, and then mirror polished using cloth polishing wheel machine with $1 \mu \mathrm{m}$ lavigated alumina powder suspension.

\subsection{Development of Coatings}

In the present study, the two coatings selected were TiAlN and AlCrN. The RCS system used to apply the coatings is shown schematically in Fig.1. The machine is equipped with 6 cathodic arc sources. Two of the six sources were used to deposit a thin, $0.3 \mu \mathrm{m}$ thick TiN sub-layer to improve adhesion of coating. The remaining four sources were employed to deposit the main layer of the coatings, which was obtained using customized sintered targets. The compositions of the targets used, coating thickness and the summary of the process parameters are presented in Table 2.

For all coatings argon (Ar) and pure nitrogen atmosphere was used during deposition. Prior to deposition all the substrates were cleaned in two steps: firstly with Ultrasonic Pre-Cleaner (Imeco, Pune, India) and secondly with Ultrasonic Cleaning Machine with 9 Tanks including hot air dryer (Oerlikon Balzers (India) Ltd.) for 1.5 Hrs.

The characterization of as coated specimens was done and will be reported in another paper i.e. XRD (Bruker AXS D-8 advance diffractometer (Germany) with $\mathrm{Cu} \mathrm{K} \alpha$ radiation), SEM-EDAX analysis of surface as well as cross-section (FEI, Quanta 200F), surface morphology (2D and 3D) of the thin films by Atomic Force Microscope (AFM, make NT-MDT, Ntegra) and micro 
hardness. The particle size of the thin films was estimated from Scherrer formula as well as from AFM analysis, which was found to be $18 \mathrm{~nm} \& 22 \mathrm{~nm}$ respectively for TiAlN coating, whereas for AlCrN coating was $25 \mathrm{~nm} \& 27 \mathrm{~nm}$ respectively.

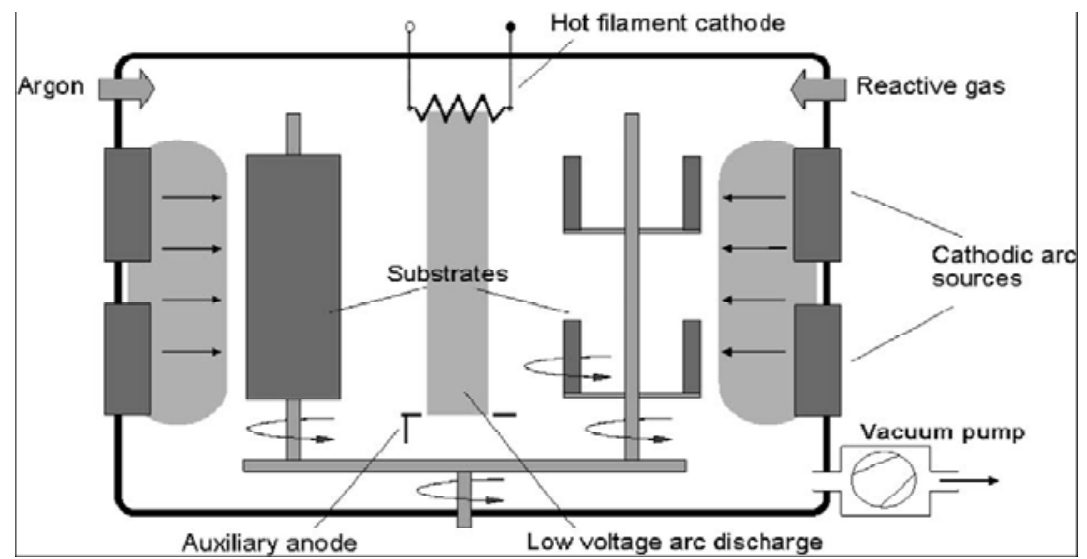

Fig.1: Schematic illustration of the coating device used for the film deposition [22]

Table 2: Summary of deposition parameters

Machine used

Make

Targets composition

Number of targets

Targets power:

Reactive gas

Nitrogen deposition pressure

Substrate bias voltage

Substrate temperature

Coating Thickness
Standard balzers rapid coating system (RCS) machine

Oerlikon Balzers, Swiss

for TiAlN coating: $\quad \mathrm{Ti}, \mathrm{Ti}_{50} \mathrm{Al}_{50}$

$$
\text { AlCrN coating: } \quad \mathrm{Al}_{70} \mathrm{Cr}_{30}
$$

$\mathrm{Ti}(02), \mathrm{Ti}_{50} \mathrm{Al}_{50}(04)$ and $\mathrm{Al}_{70} \mathrm{Cr}_{30}(06)$

$3.5 \mathrm{~kW}$

Nitrogen

$3.5 \mathrm{~Pa}$

$-40 \mathrm{~V}$ to $-170 \mathrm{~V}$

$450^{\circ} \mathrm{C} \pm 10^{\circ} \mathrm{C}$

$4 \mu \mathrm{m} \pm 1 \mu \mathrm{m}$

\subsection{Oxidation Studies in Air}

Cyclic oxidation studies in air were conducted at $900^{\circ} \mathrm{C}$ temperature in the laboratory silicon carbide furnace, calibrated up to the variation of $\pm 5^{\circ} \mathrm{C}$ for 50 cycles. Each cycle consisted of 1 
hour heating at $900^{\circ} \mathrm{C}$ followed by 20 min cooling at room temperature. The aim of cyclic loading is to create severe conditions for testing. The studies were performed for uncoated as well as coated specimens for the purpose of comparison. The uncoated specimens were subjected to mirror polishing, whereas coated specimens were subjected to wheel cloth polishing for $5 \mathrm{~min}$. After washing with acetone, the specimens along with alumina boats were then subjected to tube furnace for oxidation studies. During oxidation runs, the weight of boats along with the specimens were measured together after visual observations at the end of each cycle with the help of Electronic balance Model CB-120 (Contech, Mumbai, India) with a sensitivity of 1mg. Spalled scale, if any was also included in the weight change determination. The kinetics of corrosion was determined from the weight change measurement. After the oxidation studies, the exposed specimens were analyzed by XRD and SEM-EDAX analysis using Bruker AXS D-8 advance diffractometer (Germany) with $\mathrm{Cu} \mathrm{K} \alpha$ radiation at the scan rate of $2^{\circ} / \mathrm{min}$ for $20^{\circ}$ to $120^{\circ}$ and FE-SEM (FEI, Quanta 200F) respectively. The oxidized specimens were then cut using Buehler's Precision Diamond saw (Model ISOMET 1000, USA make) across the cross-section and mounted for the cross-sectional analysis using SEM/EDAX and elemental X-ray mapping. The kinetics of the cyclic oxidation of coated as well as uncoated specimens was determined using the thermogravimetric analysis and by evaluating the parabolic rate constants.

\section{OBSERVATIONS}

\subsection{Visual Examination}

The macrographs for Uncoated, TiAlN coated and AlCrN coated T-22 boiler steel subjected to cyclic oxidation in air at $900^{\circ} \mathrm{C}$ for 50 cycles are shown in Fig.2. For the uncoated T-22 boiler steel, a grey colored scale appeared on the surface right from the $1^{\text {st }}$ cycle. The surface appearance of the scale turned to brownish grey tone which remained till the end of $50^{\text {th }}$ cycle. This bare steel showed spalling of scale just after the $5^{\text {th }}$ cycle, which continued till the end of 50 cycles. At the end of cyclic study, irregular and fragile scale was observed with deep cracks and blackish grey color (with brownish grey appearance at some places) surface appearance, which can be seen in Fig.2. (a).

In case of TiAlN coated T-22 boiler steel, color of the oxide scale at the end of the study was observed to be grey with some blackish grey areas on the surface, as shown in Fig.2 (b). The color of the scale after $2^{\text {nd }}$ cycle was observed as whitish brown which changes to grey with golden and black spots at few areas after subsequent cycles. A fragile scale appeared on the surface of the specimen during the initial cycles. Subsequently, cracks were developed in the scale and spalling was observed during the subsequent cycles. After $20^{\text {th }}$ cycle severe swelling and peeling of the oxide scale was observed. Some of the scale was seen getting detached from the surface of the TiAlN coated T-22 boiler steel. 

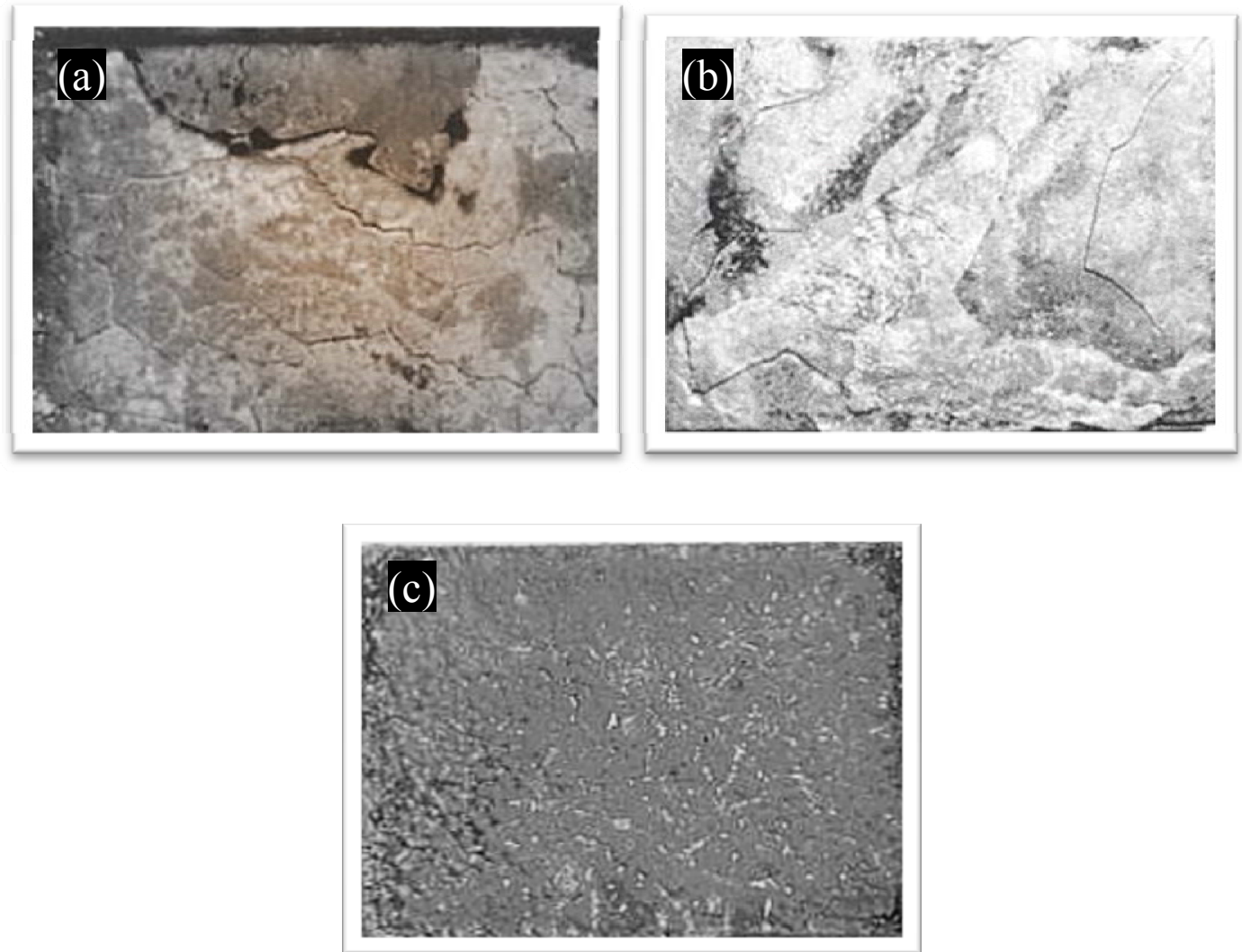

Fig.2: Surface macrographs for the T-22 boiler steel subjected to cyclic oxidation in air at $900^{\circ} \mathrm{C}$ for 50 cycles: a) uncoated, b) TiAlN coated, (c) AlCrN coated

The AlCrN coated T-22 boiler steel has shown the formation of smooth scale without the presence of cracks, when subjected to cyclic oxidation in air at $900^{\circ} \mathrm{C}$ for 50 cycles. Color of the oxide scale at the end of the study was observed to be dark grey, as shown in Fig.2 (c). The scale was found to be lustrous, with no tendency to spall. Golden and ink blue reflections were observed in the scale, after the completion of $2^{\text {nd }}$ cycle, which turned to dark grey subsequently.

\subsection{Thermogravimetric Data}

Thermogravimetric data for coated and bare T-22 boiler steel subjected to cyclic oxidation is presented in Fig. 3 in the form of a graph between weight gain per unit area $\left(\mathrm{mg} / \mathrm{cm}^{2}\right)$ versus time expressed in number of cycles. It can be inferred from the plots that the uncoated and TiAlN coated T-22 boiler steels have shown initially high rate of oxidation as compared to AlCrN coated T-22 steel, followed by a nearly constant rate. After $20^{\text {th }}$ cycle, the oxidation rate in case of TiAlN coated sample increased abruptly up to the $50^{\text {th }}$ cycle. The cumulative weight gains after completion of 50 cycles (shown in Fig.4) of oxidation are found to be 177.24, 203.39, 55.27 $\mathrm{mg} / \mathrm{cm}^{2}$ for the uncoated as well as TiAlN and AlCrN coated T-22 boiler steel, respectively. 


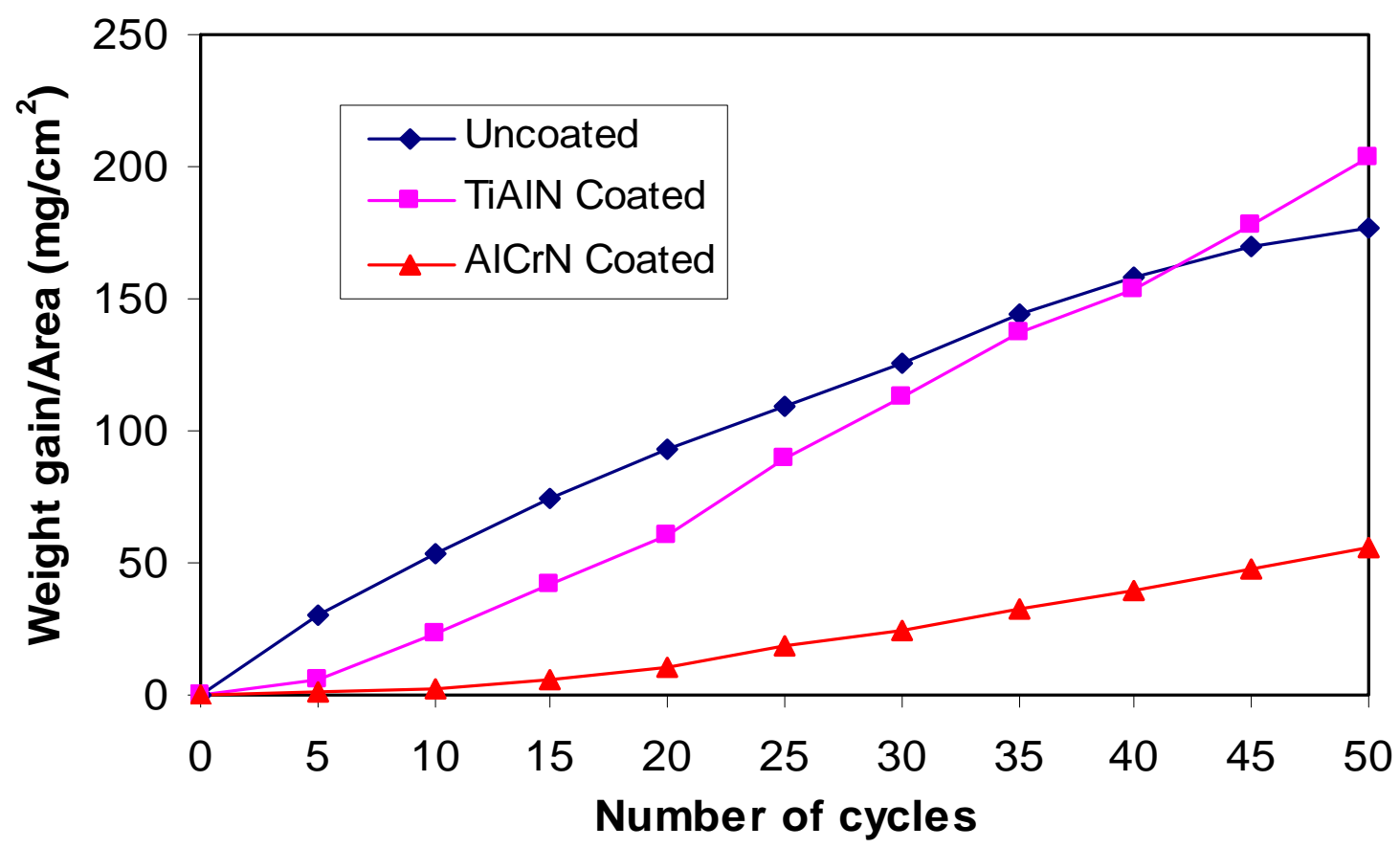

Fig.3: Weight gain per unit area vs. number of cycles plot for coated and uncoated T-22 boiler steel subjected to cyclic oxidation in air at $900^{\circ} \mathrm{C}$ for 50 cycles

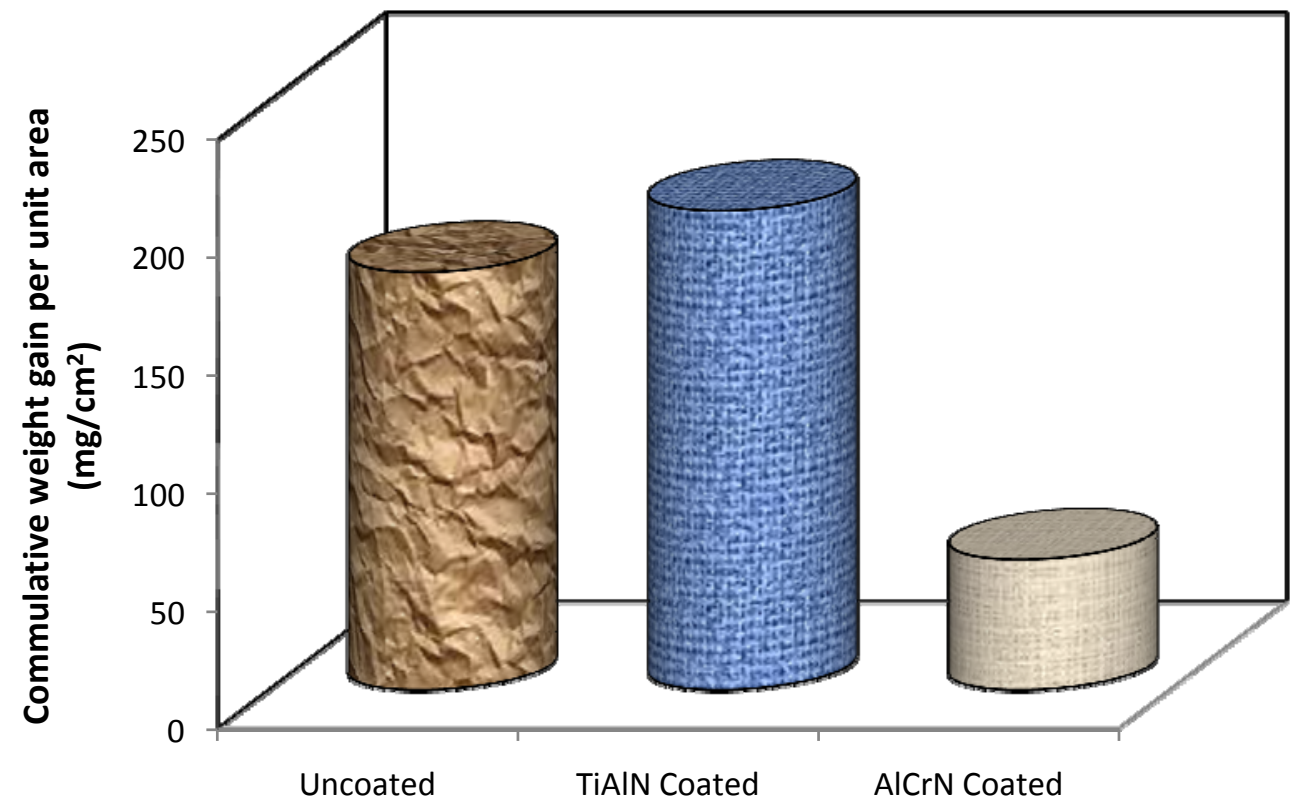

Fig.4: Bar chart showing cumulative weight gain per unit area for coated and uncoated $\mathrm{T}-22$ boiler steel subjected to cyclic oxidation in air at $900^{\circ} \mathrm{C}$ for 50 cycles 


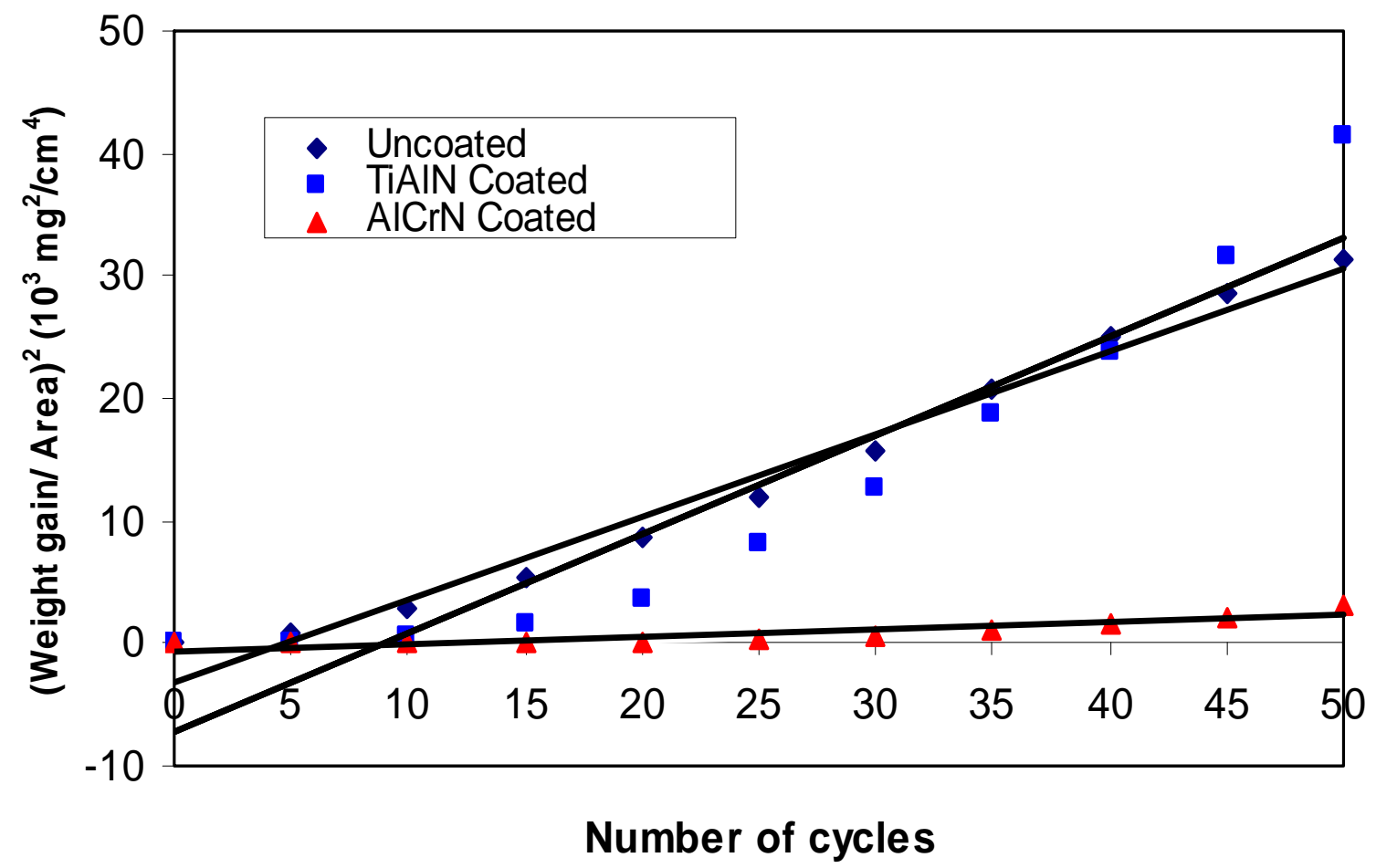

Fig.5: (Weight gain per unit area) ${ }^{2}$ vs. number of cycles plot for coated and uncoated T-22 boiler steel subjected to cyclic oxidation in air at $900^{\circ} \mathrm{C}$ for 50 cycles

Table 3: Values of parabolic rate constant for bare and coated T-22 boiler steels exposed to cyclic oxidation in air at $900^{\circ} \mathrm{C}$ for 50 cycles

\begin{tabular}{cc}
\hline Type of steel & $\mathrm{K}_{\mathrm{p}}\left(\mathrm{x} 10^{-7} \mathrm{gm}^{2} / \mathrm{cm}^{4} / \mathrm{s}\right)$ \\
\hline Uncoated T-22 & 1.88 \\
TiAlN coated & 2.25 \\
AlCrN coated & 0.15 \\
\hline
\end{tabular}




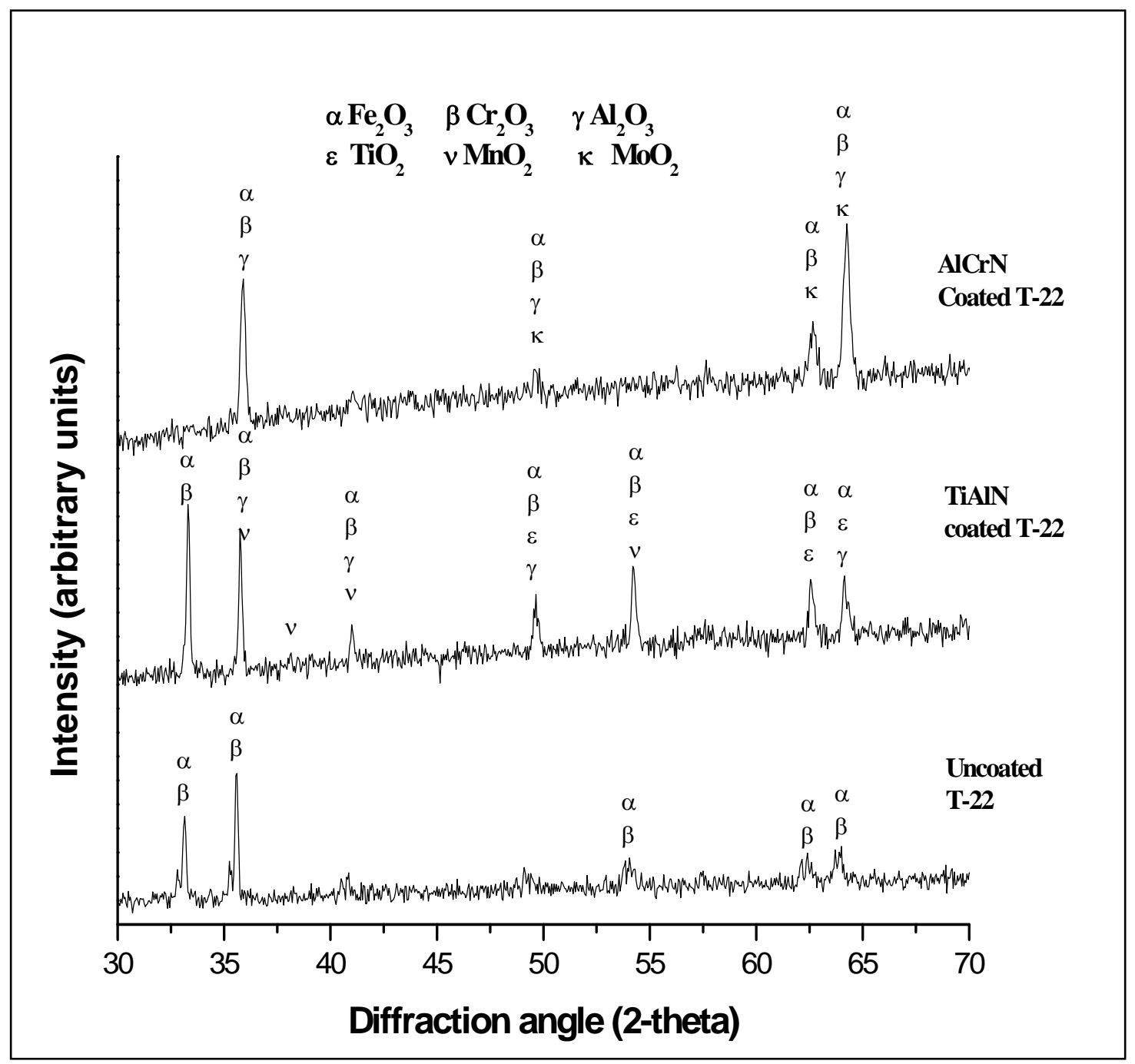

Fig.6: X-ray diffraction pattern for coated and uncoated T-22 boiler steel subjected to cyclic oxidation in air at $900^{\circ} \mathrm{C}$ for 50 cycles

As evident from Fig. 4, the overall weight gain is highest in case of TiAlN coated steel and is lowest in case of AlCrN coated steel. In Fig. 5, the (weight gain/area) ${ }^{2}$ versus number of cycles plot are shown for all the cases to ascertain conformance with the parabolic rate law. Although some scatter in the data can be observed in the plots, yet it is apparent that these data can be approximated by a parabolic relationship. There is a visible deviation from the parabolic rate law in case of TiAlN coated T-22 boiler steel, whereas the uncoated and AlCrN coated T-22 boiler steel follow the parabolic behavior up to 50 cycles. Ignoring the scatter in the data, the parabolic rate constant $\mathrm{K}_{\mathrm{p}}$ was calculated by a linear least-square algorithm to a function in the form of $(\mathrm{W} / \mathrm{A})^{2}=\mathrm{K}_{\mathrm{p}} \mathrm{t}$, where W/A is the weight gain per unit surface area $\left(\mathrm{mg} / \mathrm{cm}^{2}\right)$ and ' $\mathrm{t}$ " indicates the 
number of cycles representing the time of exposure. The parabolic rate constants for the bare and coated T-22 boiler steel calculated on the basis of 50 cycle's exposure data are shown in Table.3.

\subsection{X-ray DiffractionAanalysis (XRD)}

XRD diffractograms for coated and uncoated T-22 boiler steel subjected to cyclic oxidation in air at $900^{\circ} \mathrm{C}$ for 50 cycles are depicted in Fig. 6 on reduced scale. As indicated by the diffractograms in Fig.6, $\mathrm{Fe}_{2} \mathrm{O}_{3} \& \mathrm{Cr}_{2} \mathrm{O}_{3}$ are the main phases present in the oxide scale of uncoated $\mathrm{T}-22$ boiler steel. In case of TiAlN coated T-22 boiler steel, the formation of $\mathrm{Fe}_{2} \mathrm{O}_{3}, \mathrm{Cr}_{2} \mathrm{O}_{3}, \mathrm{Al}_{2} \mathrm{O}_{3}, \mathrm{MnO}_{2}$ and $\mathrm{TiO}_{2}$ has been indicated by XRD peaks. Further, in case of AlCrN coated T-22 boiler steel, the prominent phases are $\mathrm{Fe}_{2} \mathrm{O}_{3}, \mathrm{Cr}_{2} \mathrm{O}_{3}, \mathrm{Al}_{2} \mathrm{O}_{3}$ and $\mathrm{MoO}_{2}$.

\subsection{Surface Scale Morphology}

SEM micrographs along with EDAX analysis for coated and uncoated T-22 boiler steel subjected to cyclic oxidation in air at $900^{\circ} \mathrm{C}$ for 50 cycles are shown in Fig.7. Micrograph as shown in Fig.7 (a) for uncoated T-22 boiler steel indicates mainly white and dark phases. As indicated by the EDAX analysis the white phase shows more amount of $\mathrm{Cr}(03.78 \%), \mathrm{O}$ $(16.79 \%)$ and Mo (13.4\%) then the dark phase i.e. Cr (00.55\%), O (16.47\%) and Mo (11.55\%), whereas the dark phase is rich in $\mathrm{Fe}(62.21 \%)$ as compared to the white phase i.e. Fe (58.82). The oxide scale was fragile having some cracks in it.

The SEM micrograph and compositions of oxidized TiAlN coated T-22 boiler steel is shown in Fig.7 (b). The oxide scale is mainly consisting of three types of regions i.e. one is like white needles dispersed in matrix, second is light grey matrix and third is dark grey matrix. The top scale is rich in $\mathrm{Fe}, \mathrm{Mo}, \mathrm{O}$, and $\mathrm{Mn}$ as analyzed by EDAX analysis. The small amount of $\mathrm{Al}$, Ti, $\mathrm{Cr}, \mathrm{C}, \mathrm{Si}$, and $\mathrm{P}$ are also present. The region with white needles like appearance shows maximum amount of $\mathrm{Fe}(61.46 \%)$, moderate amount of Mo (22.21\%) and minimum amount of $\mathrm{O}(10.66 \%)$ \& Mn (02.30\%). The dark grey matrix is rich in Fe (57.40\%) with Mo (11.71\%), O (17.36\%) and Mn (05.44\%). Further, the light grey matrix shows maximum amount of Mo (42.31\%), O (20.29\%) \& Mn (12.44\%) and minimum amount of $\mathrm{Fe}(19.90 \%)$.

In case of $\mathrm{AlCrN}$ coated $\mathrm{T}-22$ boiler steel oxidized in air at $900{ }^{\circ} \mathrm{C}$ for 50 cycles, the SEM micrograph indicates the dense dimple like surface appearance along with light grey porous surface like matrix, as shown in Fig.7 (c). The EDAX point analysis shows, the top scale is rich in Fe, Mo and $\mathrm{O}$. The small amount of $\mathrm{Mn}, \mathrm{Al}, \mathrm{N}, \mathrm{Cr}, \mathrm{C}, \mathrm{Si}$, and $\mathrm{P}$ are also present. The dimple like region is rich in $\mathrm{Fe}(52.78 \%)$ along with $\mathrm{Mo}(13.27 \%), \mathrm{O}(26.63 \%)$. The porous surface like grey matrix is rich in Fe (58.35\%) along with Mo (10.32\%), O $(20.16 \%)$. The white region on the grey matrix shows maximum oxygen content i.e. O (30.30\%) along with $\mathrm{Fe}(53.39 \%)$ and Mo $(07.65 \%)$. 


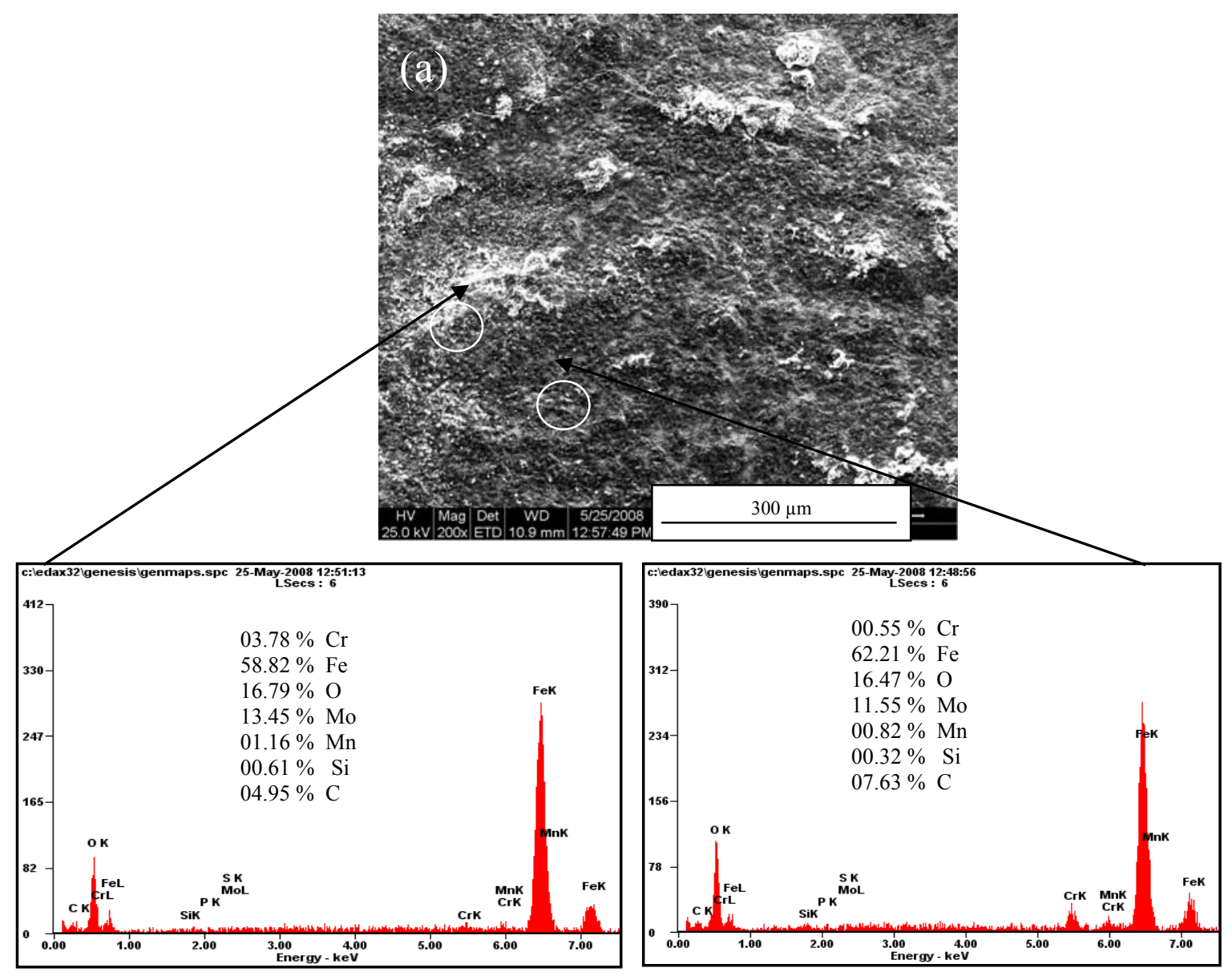

Fig.7 (a): SEM/EDAX analysis along with EDS spectrum for uncoated T-22 boiler steel subjected to cyclic oxidation in air at $900^{\circ} \mathrm{C}$ for 50 cycles (X 200) 


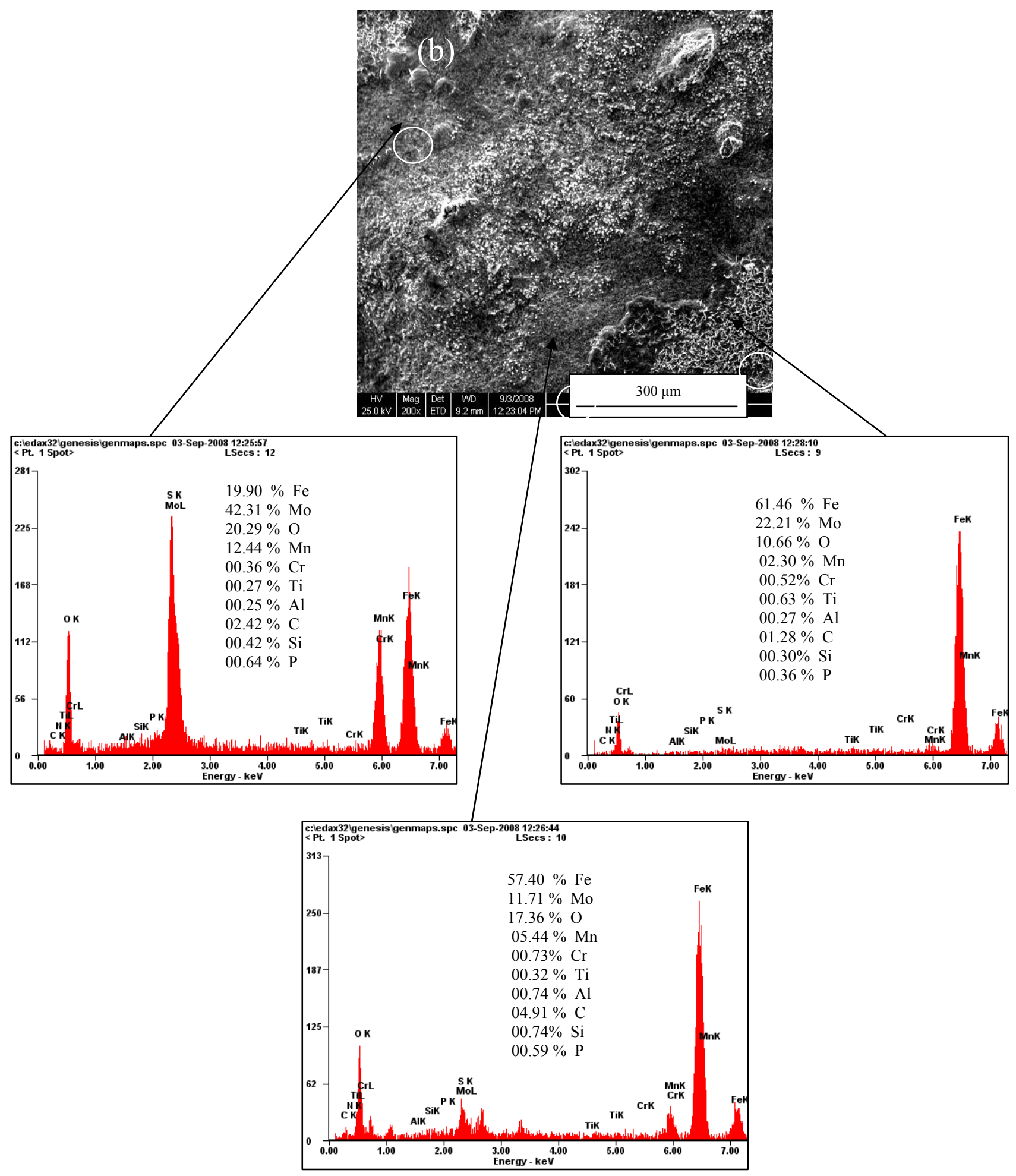

Fig.7 (b): SEM/EDAX analysis along with EDS spectrum for TiAlN coated T-22 boiler steel subjected to cyclic oxidation in air at $900^{\circ} \mathrm{C}$ for 50 cycles (X 200) 


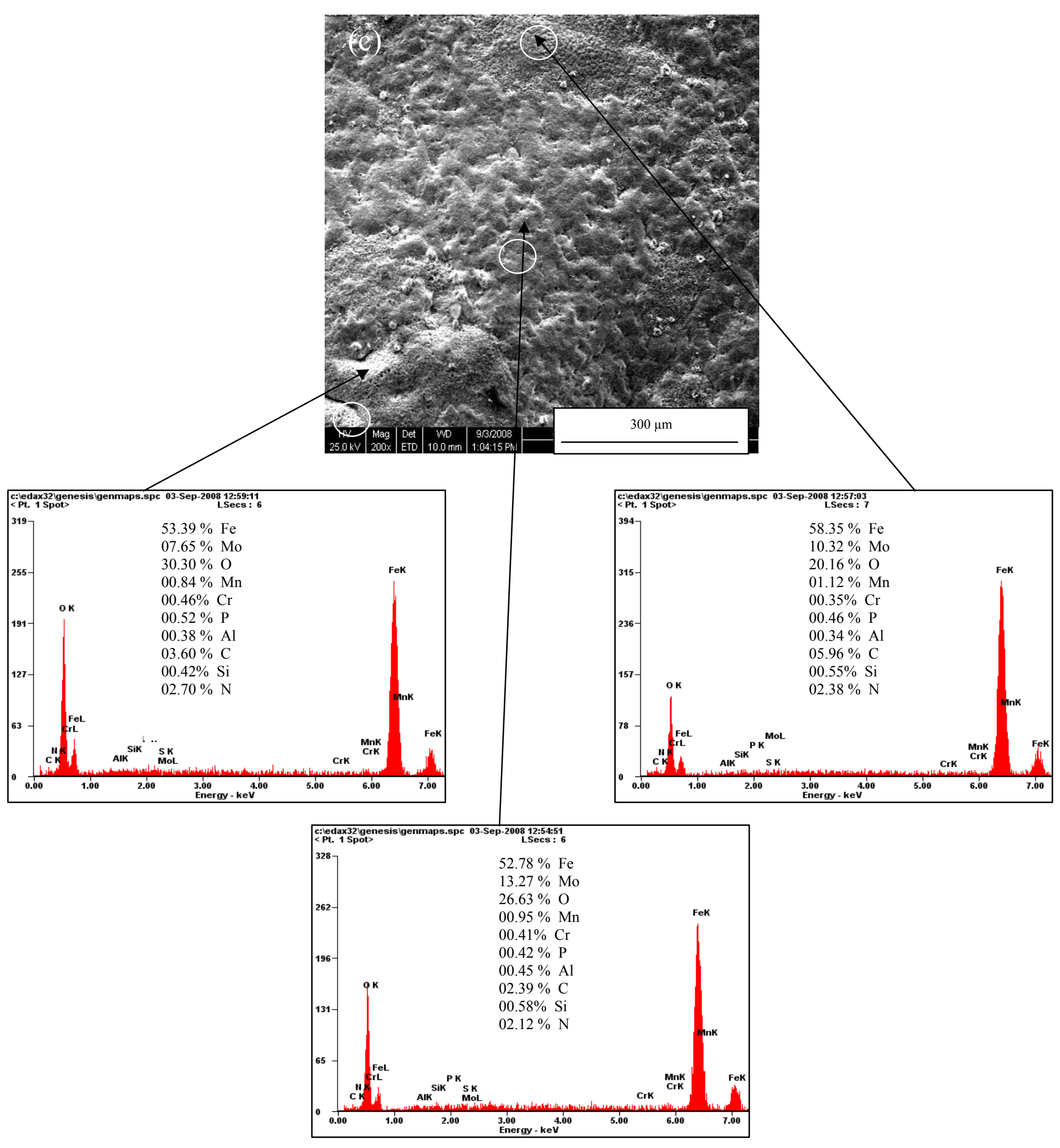

Fig.7(c): SEM/EDAX analysis along with EDS spectrum for A1CrN coated T-22 boiler steel subjected to cyclic oxidation in air at $900^{\circ} \mathrm{C}$ for 50 cycles (X 200) 


\subsection{Cross-Sectional Analysis}

\subsubsection{Scale thickness}

Scanning electron back scattered micrographs for coated and uncoated T-22 boiler steel subjected to cyclic oxidation in air at $900^{\circ} \mathrm{C}$ for 50 cycles, are presented in Fig.8. Very thick scale is observed in case of uncoated T-22 boiler steel, which is around 1.5 times \& and 7.69 times thicker than the scale measured for TiAlN coated and AlCrN coated T-22 boiler steel respectively. The measured oxide scale thickness for the oxidized specimens is shown in Table.4.

\subsubsection{Cross-sectional scale morphology}

Back Scattered Electron Image (BSEI) micrograph and elemental variation across the crosssection for coated and uncoated T-22 boiler steel subjected to cyclic oxidation in air at $900^{\circ} \mathrm{C}$ for 50 cycles are shown in Fig.8. The SEM micrograph in case of uncoated T-22 boiler steel shows thick scale as shown in Fig. 8 (a). EDAX analysis reveals the presence of Fe, $\mathrm{Cr}$ and oxygen throughout the scale. The EDAX analysis shows the contrast grey phase (point 4 and 6) mainly consist of $\mathrm{Cr}$ and $\mathrm{Fe}$. The existence of significant amount of oxygen points out the possibility that this grey phase may be rich in $\mathrm{Cr}_{2} \mathrm{O}_{3}$ and $\mathrm{Fe}_{2} \mathrm{O}_{3}$. The top portion of the scale (point 2) mainly contains $\mathrm{Fe}$ and $\mathrm{O}$ and little amount of $\mathrm{Mn}, \mathrm{Cr}, \mathrm{P}$, and $\mathrm{Si}$. BSEI micrograph and elemental variation depicted in Fig.8 (b), for the exposed cross-section of TiAlN coated T-22 boiler steel shows the thick scale. The EDAX analysis reveals the presence of Fe, Mo and oxygen through out the scale. So, iron oxide and molybdenum oxide are the main phases in the oxide scale. At point 4 about $6 \mathrm{wt} \%$ of $\mathrm{Cr}$ is present along with of good percentage of oxygen (about $32 \mathrm{wt} \%$ ), which indicates the possible presence of $\mathrm{Cr}_{2} \mathrm{O}_{3}$. The outer portion of the scale is rich in $\mathrm{Fe}$ and Mo oxides, whereas in the middle of the scale existence of $\mathrm{Cr}_{2} \mathrm{O}_{3}$ is indicated (point 4). BSEI micrograph and elemental variation for $\mathrm{AlCrN}$ coated $\mathrm{T}-22$ boiler steel is shown in Fig.8(c). A continuous and adherent oxide scale can be seen. The presence of oxygen at the scale substrate interface may be due to the in flight oxidation of coating or oxygen might have penetrated during initial cycles of oxidation run along the intersplat boundaries.

Table 4: Average scale thickness ( $\mathrm{mm}$ ) for uncoated and coated T-22 boiler steels exposed to cyclic oxidation in air at $900^{\circ} \mathrm{C}$ for 50 cycles.

\begin{tabular}{cc}
\hline Type of steel & thickness $(\mathrm{mm})$ \\
\hline & \\
Uncoated T-22 & 1.00 \\
TiAlN coated & 0.64 \\
AlCrN coated & 0.13 \\
\hline
\end{tabular}



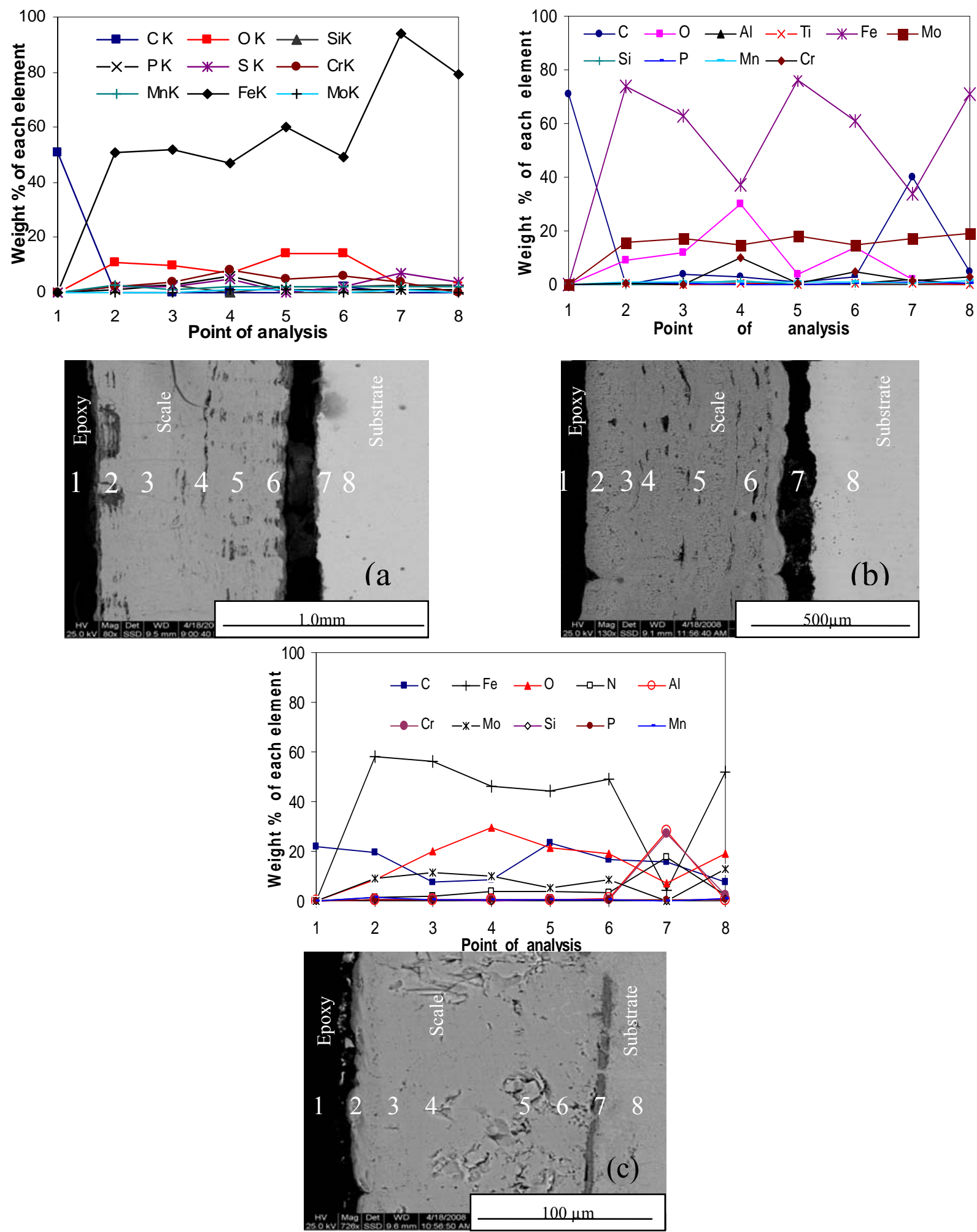

Fig.8: Oxide scale morphology and variation of elemental composition across the cross-section of coated and uncoated T-22 boiler steel subjected to cyclic oxidation in air at $900^{\circ} \mathrm{C}$ for 50 cycles, (a) Uncoated (X 80); (b) TiAlN coated (X 130); (c) AlCrN coated (X 726). 
The EDAX analysis indicates the presence of Fe, Mo and oxygen through out the scale. The outer portion of the scale is rich in Fe, Mo and oxygen. Thin band of AlCrN coating (point 7) is seen between substrate and scale. This thin band at scale substrate interface (dark grey line) mainly contains Al, Cr, N and very less Fe, Mo and oxygen (point 7). At some points thin film has gaps; Fe and Mo have moved through the openings and got oxidized to form the scale.

\subsubsection{X-Ray mapping}

BSEI and X-ray mapping for a part of oxide scale of uncoated T-22 boiler steel oxidized in air at $900{ }^{\circ} \mathrm{C}$ for 50 cycles are shown in Fig. 9. The micrograph indicates a dense scale, which mainly contains iron and oxygen with some amount of chromium, as indicated by X-ray mapping. Oxygen is present throughout the scale. The BSEI and X-ray mapping analysis of the scale formed on TiAlN coated T-22 boiler steel is presented in Fig. 10. The BSE image indicates the formation of a dense scale consisting mainly of iron, oxygen and chromium with small amounts of titanium and manganese. The X-ray mapping indicates thin irregular bands of $\mathrm{Cr}$ parallel to each other, where $\mathrm{Cr}$ is present $\& \mathrm{Fe}$ is absent.

In case of AlCrN coated T-22 boiler steel subjected to cyclic oxidation in air, the BSEI and Xray mapping are shown in Fig. 11. The scale formed is dense and adherent to the substrate without any crack in the scale or at substrate-scale interface. The X-ray mapping indicates the presence of iron and oxygen throughout the scale. A thin band of $\mathrm{Al}, \mathrm{Cr}$ and $\mathrm{N}$ is also indicated by X-ray mapping, where iron and oxygen are completely absent.

\section{DISCUSSION}

Nearly parabolic behaviour followed by the coated and bare steels during cyclic oxidation study. The parabolic kinetic behavior is due to the diffusion controlled mechanism operating at $900^{\circ} \mathrm{C}$ under cyclic conditions [13]. Small deviation from the parabolic rate law might be due to the cyclic scale growth. The higher weight gain during the first few cycles might be attributed to the rapid formation of oxides at the splat boundaries and within the open pores due to the penetration of the oxidizing species, further the subsequent increase in weight is gradual [14]. The parabolic rate constant for the TiAlN coated T-22 boiler steel is found to be greater then the uncoated and AlCrN coated T-22 boiler steel.

AlCrN coating has been found successful in reducing the overall weight gain of bare T-22 boiler steel by $69 \%$. The oxidation rate (total weight gain values after 50 cycles) of the coated and uncoated T-22 boiler steel follows the sequence as given below:

\section{TiAlN coating $>$ Uncoated $>$ AlCrN coating}

During cyclic testing, cracks in the oxide scale (Fig.7.a) and spalling of the coatings might be attributed to the different values of thermal coefficients for the coating and the substrate as 
reported by Buta Singh Sidhu et al. [15], Harpreet Singh et al. [4], Evans \& Taylor [16], Wang et al. [17] and Niranatlumpong et al [18].
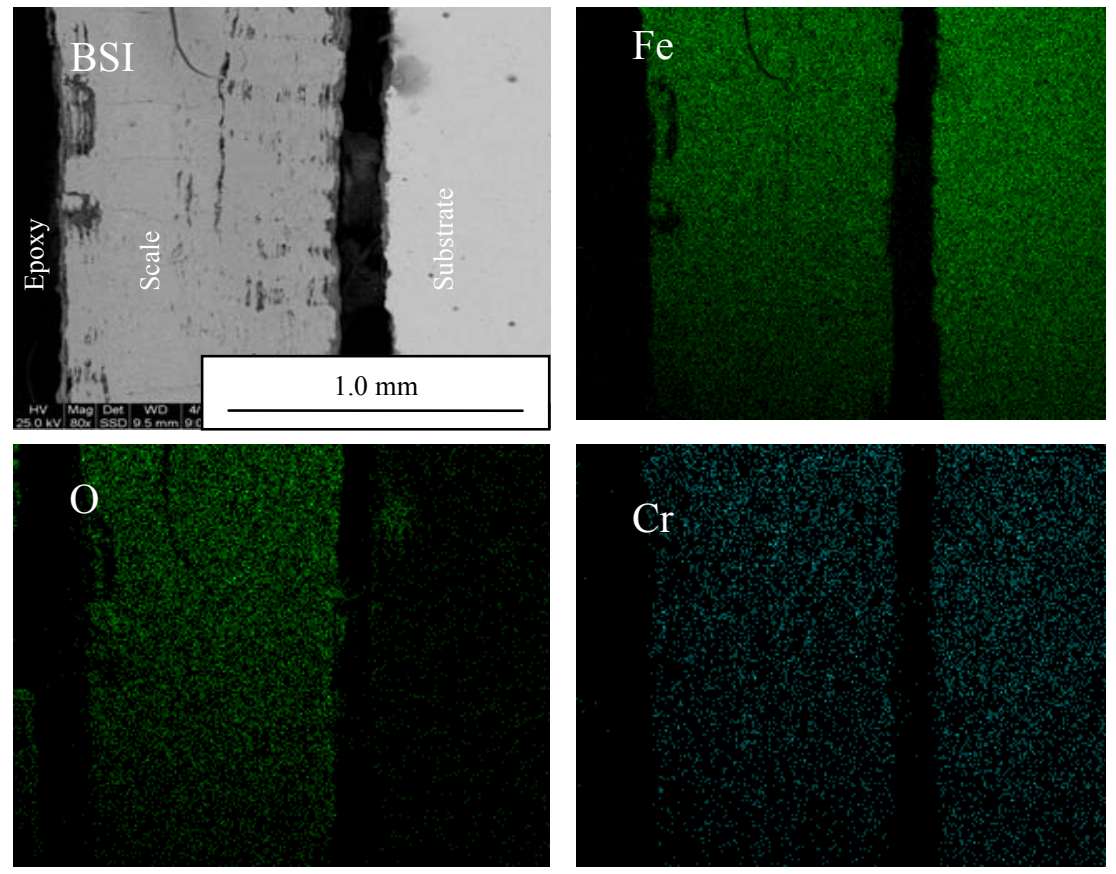

Fig. 9: Composition image (BSI) and X-ray mapping of the cross-section of the uncoated T-22 boiler steel subjected to cyclic oxidation in air at $900^{\circ} \mathrm{C}$ for 50 cycles (X 80).

Further Niranatlumpong et al. [18] opined that spallation could be initiated by the rapid growth of void-like defects lying adjacent to coating protuberances, at which tensile radial stress developed during cooling as a result of the thermal contraction mismatch between the oxide and coating is maximum. The formation of cracks in the coating originates from stresses developed in the deposit or at the coating-base metal interface [19]. Though these cracks the corrosive environment can quickly reach the base metal and cut its way under the coating to result in adhesion loss and spalling, whereas some elements may diffuse outwards through these cracks to form their oxides or spinels [4]. The presence of Fe, Mo and oxygen (Fig.7.a,b and c) in the top of the scale, is believed to be due to the diffusion of iron and molybdenum through the pores and cracks that appeared in the coating during the course of oxidation studies [15].

Inferior oxidation resistance of TiAlN coating may be as opined by Xing-zhao Ding et al. [20]. According to them, in an oxidation or corrosive environment $\mathrm{Ti}$ element often forms a porous non-protective oxide scale, which limits the oxidation and corrosion resistance of titanium-based coatings. This has further been reported by Kazuhisa Fujita [21], where authors have reported 
that the oxide scale of binary TiAl alloy is composed of a porous oxide mixture of $\mathrm{TiO}_{2}$ and $\mathrm{Al}_{2} \mathrm{O}_{3}$, which has dominated by $\mathrm{TiO}_{2}$. This might be the reason for rapid increase in oxidation rate of TiAlN coatings after $20^{\text {th }}$ cycle (Fig. 3 ).
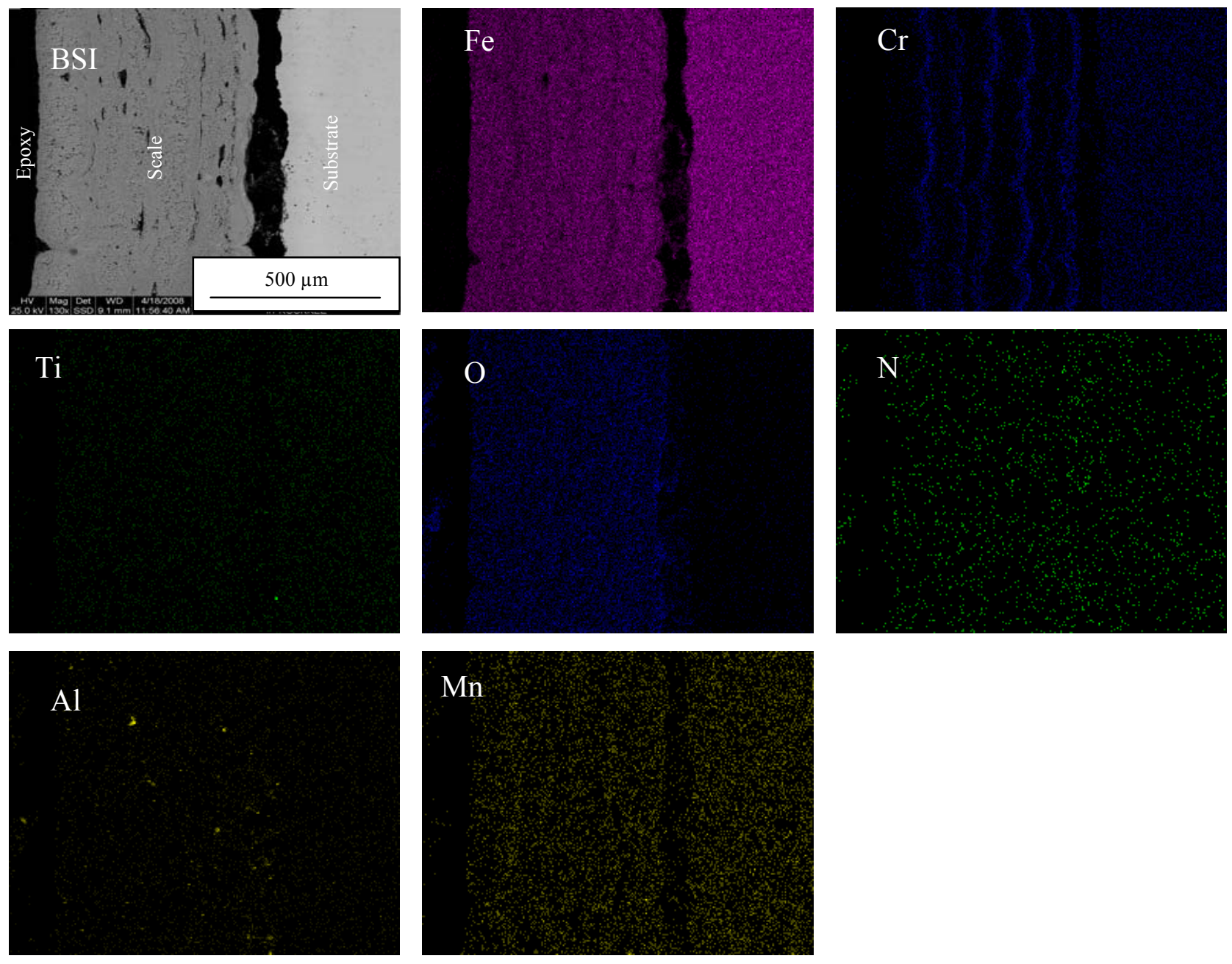

Fig.10: Composition image (BSI) and X-ray mapping of the cross-section of the TiAlN coated $\mathrm{T}-22$ boiler steel subjected to cyclic oxidation in air at $900^{\circ} \mathrm{C}$ for 50 cycles (X 130).

W. Kalss et al. [22] have reported, at $900{ }^{\circ} \mathrm{C}$ an oxidized layer of thickness of about $350 \mathrm{~nm}$ for TiAlN coating was measured. Due to high temperature the segregation of titanium and aluminum atoms is probable. Evidently, high temperature oxidation involved diffusion of aluminum atoms to the surface to form a thin aluminum oxide top layer while the remaining titanium under layered formed titanium dioxide. At $950{ }^{\circ} \mathrm{C}$, the whole coating was decomposed and pure titanium dioxide was formed [22], which is supported by B.Y. Man et al.[23] as they have 
reported at $900^{\circ} \mathrm{C}$ a peak ascribed to $\mathrm{Fe}_{2} \mathrm{O}_{3}$ oxide, which corresponds to a failure of the TiAlN coating.
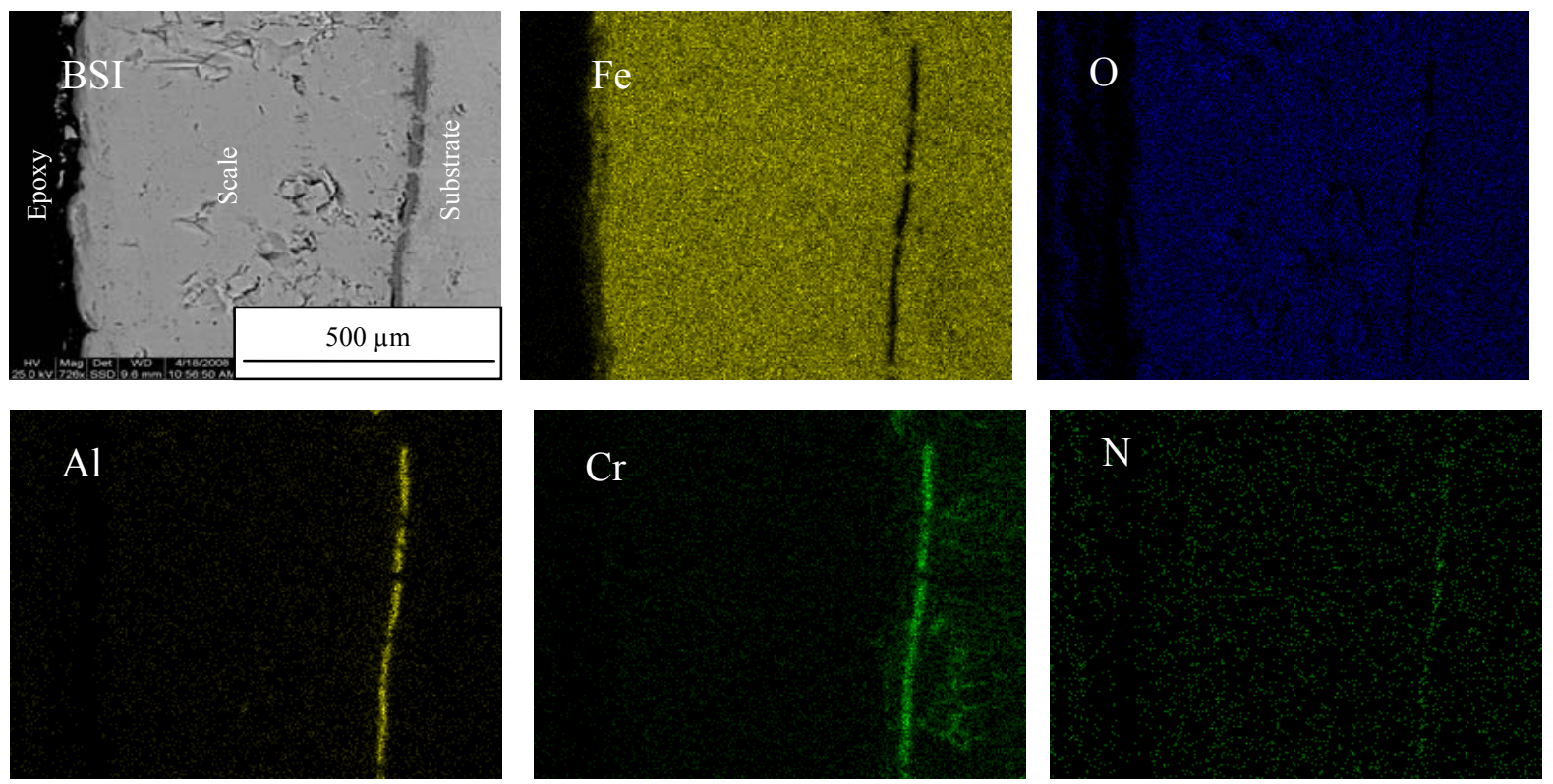

Fig.11: Composition image (BSI) and X-ray mapping of the cross-section of the AlCrN coated T-22 boiler steel subjected to cyclic oxidation in air at $900^{\circ} \mathrm{C}$ for 50 cycles $(\mathrm{X} 726)$.

The presence of $\mathrm{Fe}_{2} \mathrm{O}_{3}$ in the upper layer of the scale is followed by a subscale in which $\mathrm{Fe}_{2} \mathrm{O}_{3}$ and $\mathrm{Cr}_{2} \mathrm{O}_{3}$ are present, as indicated by the XRD (Fig.6), EDAX (Fig. 8.b) and X-ray mapping (Fig. 10). Figure 10 indicated the presence of $\mathrm{Cr}$ in the subscale along with oxygen and iron. This can be attributed to the depletion of iron due to oxidation to form the upper scale, thereby leaving chromium-rich pockets those have further oxidized to form parallel and irregular chromium oxide bands [15]. These bands of chromium oxide may have prevented the deep penetration of the environment, as the scale thickness is less in case of oxidized TiAlN coated T-22 boiler steel then that of uncoated boiler steel.

The surface morphology, Fig. 7(c), of T-22 steel oxidized after coating with AlCrN indicates the dense dimple like surface appearance along with light grey porous surface like matrix. The EDAX point analysis shows, the top scale is rich in Fe, Mo and O. The scale formed is dense and adherent to the substrate without any crack in the scale or at substrate-scale interface. A thin band of $\mathrm{Al}, \mathrm{Cr}$ and $\mathrm{N}$ is indicated by cross-sectional EDAX analysis (Fig.8.c) and X-ray mapping (Fig.11), where iron and oxygen are completely absent. It clearly shows that coating remains adherents to the substrate during the course of oxidation run. At some points thin film has gaps; 
Fe and Mo have moved through the openings and got oxidized to form the scale. Further good oxidation resistance for this type of coating has also been observed by W. Kalss et al. [22].

\section{CONCLUSIONS}

The $\mathrm{AlCrN}$ coating has provided good resistance against oxidation in air at $900{ }^{\circ} \mathrm{C}$ for 50 cycles and provided the necessary protection to the base metal. The oxidation rate (total weight gain values after 50 cycles) of the coated and uncoated T-22 boiler steel followed the sequence:

\section{TiAlN coating $>$ Uncoated $>$ AlCrN coating}

The AlCrN coating has sustained during the course of oxidation study. At some points thin film has gaps; Fe and Mo have moved through the openings and got oxidized to form the scale. The TiAlN coating has failed to provide the protection to the base metal during the oxidation. This might be due to the formation of oxide scale which is composed of a porous oxide mixture of $\mathrm{TiO}_{2}$ and $\mathrm{Al}_{2} \mathrm{O}_{3}$, with the domination of $\mathrm{TiO}_{2}$. The internal oxidation has been observed in all the cases. The difference in thermal expansion coefficients between oxides, coating and base steel perhaps led to the cracking of the oxide scale and coatings.

\section{ACKNOWLEDGEMENT}

The authors wish to thank All India Council for Technical Education (A.I.C.T.E.), New Delhi, India for providing National Doctoral Fellowship (NDF) to Dr. Vikas Chawla (corresponding author) and Nationally Coordinated Project (NCP).

\section{REFERENCES}

[1] W. Brandl, G. Marginean, D. Maghet, D. Utu, Surf. \& Coat. Technol. 188-189 (2004) 2026.

[2] L. Fedrizzi , S. Rossi , R. Cristel , P.L. Bonora , Elect. Chem. Acta 49 (2004) 2803-2814.

[3] Harpreet Singh, D. Puri and S. Prakash, Anti. Corros. Method Mater. 52/2 (2005) 84-95.

[4] Harpreet Singh, D. Puri and S. Prakash, International Symposium of Research Students on Materials Science and Engineering, December 20-22, 2004, Indian Institute of Technology Madras, Chennai, India.

[5] G. Bertrand, H. Mahdjoub, C. Meunier, Surf. \& Coat. Technol. 126 (2000) 199-209.

[6] L. Cunha, M. Andritschky , L. Rebouta , K. Pischow, Surf. \& Coat. Technol. 116-119 (1999) 1152-1160.

[7] Xing-zhao Ding, A.L.K. Tan, X.T. Zeng, C. Wang, T. Yue, C.Q. Sun, Thin Solid Films 516(2008) 5716-5720.

[8] Yun Ha Yoo, Diem Phuong Le, Jung Gu Kim, Sun Kyu Kim, Pham Van Vinh, Thin Solid Films 516 (2008) 3544-3548.

[9] F. Quesada, A. Mariño, E. Restrepo, Surf. \& Coat. Technol. 201 (2006) 2925-2929. 
[10] E. Spain, J.C. Avelar-Batista, M. Letch, J. Housden, B. Lerga, Surf. \& Coat. Technol. 200 (2005) $1507-1513$.

[11] J.L. Endrino, G.S. Fox-Rabinovich, A. Reiter, S.V. Veldhuis, R. Escobar Galindo, J.M. Albella, J.F. Marco, Surf. \& Coat. Technol. 201 (2007) 4505-4511.

[12] B.R. Marple, J. Voyer, J. F. Bisson, C. Moreau, J. Mater. Process. Technol. 117 (2001), 418-423.

[13] R.A. Mahesh, R. Jayaganthan, S. Prakash, Mater. Sci. Engg. A, 475 (2008) 327-335.

[14] H. Singh, S. Prakash, D. Puri, Mater. Sci. Engg. A, 444 (2007) 242-250.

[15] Buta Singh Sidhu, S. Prakash, Surf. \& Coat. Technol. 166 (2003) 89-100.

[16] Evans H E, and Taylor M P, Oxid. Met. 55 (1-2) (2001).

[17] Wang B, Gong J, Wang A Y, Sun C, Huang R F, and Wen L S, Surf. \& Coat. Technol. 149 (2002) 70-75.

[18] Niranatlumpong P, Ponton C B, and Evans H E, Oxid. Met., 53 (3-4) (2000) 241.

[19] Heath G R, Heimgartner P, Irons G, Miller R, and Gustafsson S, Mater. Sci. Forum, 251254 (1997) 809.

[20] Xing-zhao Ding, A.L.K. Tan, X.T. Zeng, C. Wang, T. Yue, C.Q. Sun, Thin Solid Films 516, issue 16(2008) 5716-5720.

[21] Kazuhisa Fujita, Surf. \& Coat. Technol. 196 (2005) 139- 144.

[22] W. Kalss , A. Reiter, V. Derflinger, C. Gey, J.L. Endrino, Int. J. Refract. Metals \& Hard Mater. 24 (2006) 399-404.

[23] B.Y. Man, L. Guzman, A. Miotello, M. Adami, Surf. \& Coat. Technol. 180 -181 (2004) 914. 